\title{
O FAZER TRADUTÓRIO EM ABSTRACTS DE PERIÓDICOS CIENTÍFICOS: CONTRIBUIÇÕES DA SEMIÓTICA FRANCESA
}

\section{THE TRANSLATIONAL DOING IN ABSTRACTS OF SCIENTIFIC JOURNALS: CONTRIBUTIONS OF FRENCH SEMIOTICS}

BRUNO SAMPAIO GARRIDO ${ }^{1}$

RESUMO: Este trabalho tem como objetivo principal discorrer sobre alguns aspectos da teoria semiótica francesa que se convergem com os estudos da tradução, de maneira a alargar as perspectivas desse último campo de estudo e, assim, contribuir para o desenvolvimento de pesquisas em semiótica na área tradutológica. 0 artigo em questão, além de seguir uma perspectiva analítico-descritiva, fundamentada em pesquisa bibliográfica, pautou-se pela aplicação dos conceitos em um corpus pré-determinado - mais especificamente, quatro resumos e abstracts de artigos científicos da área de psicologia. Mediante uma perspectiva enunciativa, o tradutor é compreendido como um agente copartícipe na construção de sentidos do enunciado traduzido, não se restringindo à

1 Doutorando no Programa de Pós-graduação em Linguística e Língua Portuguesa da UNESP - Universidade Estadual Paulista. E-mail: bgarrido@fc.unesp.br. 
transposição de significados já dados. A práxis enunciativa da tradução, sob esse ângulo, pode se pautar por uma orientação mais conservadora e literal, voltada especialmente para textos de cunho referencial, ou um posicionamento mais libertário, principalmente em textos literários e poéticos. No corpus analisado, percebe-se que a literalidade, apesar de configurarse como prática predominante, se revelou entrecortada por gestos mais liberais, que exigiram modificações na estrutura léxico-gramatical do texto-fonte e, em certos casos, em reordenamentos semânticos mais significativos, embora o sentido global do texto original tenha sido preservado.

PALAVRAS-CHAVE: Tradução; Semiótica francesa; Enunciação; Práxis enunciativa; Tradução técnico-científica.

ABSTRACT: The objective of this work is to discuss about some aspects of French Semiotics theory which converge with Translation Studies, in order to widen the perspectives about that study field and, thus, contributing to Semiotics research development on Translation area. This article, besides following an analytical-descriptive view, is able to apply those concepts to a previously determined corpus more specifically four abstracts of scientific papers related to Psychology area. Through an enunciative perspective, the translator is understood as a "coparticipating" agent in meaning construction of the translated utterance, not limited to the translation of meanings already given. The enunciation praxis of translation, from this angle, can be directed by a more conservative and literal guidance, specially focused on referential texts, or a more libertarian positioning, mainly in literary and poetical texts. After analyzing the corpus, it was realized that, despite of literalness is configured as the prevailing practice, it was intersected by more liberal gestures, which required 
changes on lexicogrammatical structure of source text and, in some cases, more significant semantic reorderings, although the original text's meaning essence has been preserved.

KEYWORDS: Translation; French Semiotics; Enunciation; Enunciation praxis; Technical-scientific translation.

\section{Introdução}

Nos estudos da linguagem, a semiótica e a tradução se desenvolveram robustamente e se consolidaram como campos próprios de estudo e pesquisa. A primeira, nascida a partir das teorias linguísticas estruturais, em diálogo com as teorias da narrativa, a fenomenologia e a antropologia, rompeu os liames dos sistemas linguísticos para se voltar ao estudo dos mecanismos geradores da significação em qualquer linguagem, verbal ou não. A segunda, cuja sistematização deuse mais recentemente, volta-se a um campo mais aplicado, dedicado a transpor os elementos significantes de um objeto produzido em uma língua de origem para uma segunda língua - a de destino. Essa tarefa, mais posteriormente, também passou a considerar a transcodificação de sistemas, em que textos produzidos em uma linguagem (ex: uma obra literária) são vertidos para outra (cinema, teatro, etc.).

Logo, pode-se dizer que ambas as disciplinas se aproximam quando, cada uma à sua maneira, preocupam-se com o sentido das linguagens com as quais trabalham. Enquanto a semiótica volta-se a analisar e descrever as estruturas significantes fundamentais de um texto, a tradução visa a transpor o sentido deste para outra língua. É curioso, entretanto, constatar que essa proximidade entre semiótica e tradução não foi devidamente explorada no contexto brasileiro, sendo muito difícil encontrar obras que tratem de ambos os assuntos de 
forma integrada. Há que se falar, portanto, em uma grande lacuna a ser preenchida.

Assim, este trabalho pretende contribuir para alargar as discussões sobre o assunto, ao tentar evidenciar alguns possíveis entrecruzamentos entre a teoria semiótica e os estudos da tradução. Isso se dará mediante um ensaio teórico, fundamentado em obras clássicas da linguística contemporânea, em diálogo com os estudos semióticos e tradutológicos. Como forma de circunscrever essa temática devido às limitações de espaço desta pesquisa, os conceitos discutidos ao longo do estudo serão aplicados a um corpus previamente selecionado, constituído de resumos e abstracts de artigos científicos da área de psicologia, priorizando aspectos pertinentes às escolhas lexicais e à organização sintático-semântica dos textos na transposição dos sentidos de uma língua-origem para uma língua-alvo.

O objetivo principal deste artigo é discorrer sobre os principais aspectos da teoria semiótica francesa que se convergem com os estudos da tradução, de maneira a alargar as perspectivas desse último campo de estudo e, assim, contribuir para o desenvolvimento de pesquisas em semiótica na área tradutológica. Este trabalho, além de seguir uma perspectiva analítico-descritiva, fundamentada em pesquisa bibliográfica, se pautará pela aplicação dos conceitos em um corpus pré-determinado - mais especificamente, resumos e abstracts de artigos científicos da área de psicologia.

A principal justificativa para este tema é a escassez de estudos na área de semiótica acerca dos fenômenos tradutológicos, salvo alguns esforços individuais, porém tímidos, 
como o artigo de Pondian² (2009), que inicia uma incursão nesse campo a partir da recuperação de fundamentos presentes nas teorias linguísticas estruturais. Por se tratar de um arcabouço teórico voltado aos estudos da significação, isto é, de descrever como as variadas linguagens a geram, causa estranhamento o fato de esse caminho ainda não ser devidamente desbravado.

Logo, pretende-se aqui contribuir para o fim acima descrito, voltando-se a apontar caminhos, ainda que de forma bastante circunscrita, que pretendam conjugar esses campos de pesquisa, de modo a estabelecer uma perspectiva vigorosa e metodologicamente bem estruturada nos estudos em tradução, que teria muito a se enriquecer com o arcabouço teórico da semiótica francesa, desenvolvida pelo linguista lituano Algirdas Julien Greimas e por diversos colaboradores mundo afora.

\section{Teorias Linguísticas e Tradução - Aproximações}

Inicialmente, convém destacar a pertinência do trabalho de Mounin (1975) pelo fato de este configurar-se como um esforço relevante de apresentar a influência e importância das concepções linguísticas para os estudos da tradução, de modo a constituí-la, enfim, como um campo científico - mes-

20 trabalho desta autora teve por princípio apresentar as bases linguísticas para se almejar uma perspectiva semiótica acerca da tradução. Entretanto, as discussões apresentadas restringiram-se às teorias de base linguística fundadoras do legado greimasiano - ou seja, a linguística estrutural de Saussure e Hjelmslev - e mais outros autores contemplados. A incursão propriamente dita na teoria semiótica ocorreu apenas nas considerações finais, o que não possibilitou um aprofundamento das discussões necessárias para fundamentar o objetivo da autora. Não obstante o fato de o artigo de Pondian (2009) ser uma comunicação apresentada em congresso e, portanto, sujeito às limitações desse gênero, uma inserção mais densa nos estudos em semiótica propriamente ditos seria fundamental para justificar o intento da pesquisadora, assim como para o estudo em questão apresentar conclusões mais significativas. 
mo que, sob esse prisma, atrelado aos estudos linguísticos. Isso se mostra necessário pelo fato de as práticas tradutórias, apesar de remontarem à Antiguidade, começarem a ser pensadas e estruturadas como um campo de estudos a partir da segunda metade do século XX, afastando-se de uma concepção que entende essa atividade apenas como uma manifestação artística.

Um elemento importante apresentado por Mounin (1975), logo no início de seu trabalho, é descrever o tradutor (ou a atividade tradutória) como um lugar de interseção entre culturas, representadas pela língua de origem e a língua de destino, em que se busca equilibrar as diferenças estruturais e socioculturais de ambos os idiomas - já que, segundo o autor, há interferência da segunda sobre a primeira - com vistas à viabilidade do ato de traduzir. Logo, esse autor rejeita abordagens como as de Bloomfield, Sapir e Whorf e, até certo ponto, de Jakobson (no que tange à tradução poética), que apontam impossibilidades para o processo tradutório, em virtude da variedade com que as línguas "recortam" e interpretam o mundo natural, e cujas estruturas lexicais, sintáticas e semânticas podem se diferir radicalmente umas das outras, inviabilizando sua "passagem" para outra língua.

Mounin (1975), assim como estudos linguísticos caudatários de Saussure (2006), refuta também a premissa de que a linguagem é uma mera representação da realidade, e que existe uma relação de dependência entre o signo linguístico (significante + significado) e o seu referente no mundo natural - segundo a designação de Greimas (1975). Por essa perspectiva, as línguas se resumiriam a meras "nomenclaturas" ou "reservas de etiquetas", em que as palavras seriam apenas repositórios de significados já dados previamente, independentemente das diferenças formais entre os sistemas, o que 
não ocorre de fato (HJELMSLEV, 2009). Soma-se a isso, aponta Jakobson (1977), a premissa de que somente seria possível conhecer uma língua a partir de uma experiência concreta, de um conhecimento empírico e extralinguístico acerca do referente. Com isso, o processo tradutório estaria comprometido de imediato.

Essas afirmações supracitadas não se sustentam cientificamente, como demonstram Saussure (2006) e Hjelmslev (2009), em virtude do princípio do valor linguístico, em que o valor de cada termo se dá pelas diferenças existentes entre os demais em um sistema linguístico, e esse múltiplo reconhecimento mútuo dos papéis de cada elemento nesse conjunto (a língua) é que determina seus respectivos sentidos. Isso se dá pela função semiótica, que organiza os elementos do plano de expressão (sensível) com os do plano de conteúdo (inteligível), mediante uma relação de solidariedade/interdependência entre si e de arbitrariedade em relação ao referente externo (os objetos do mundo natural). Logo, diferentes sistemas linguísticos compartilhariam entre si sentidos em comum, a despeito das diferenças formais entre um e outro o que viabilizaria, desse modo, o processo de tradução. Como frisa Hjelmslev,

Em diferentes línguas, as cadeias, apesar de todas as diferenças, têm um fator comum: o sentido ${ }^{3}$, o mesmo pensamento que, assim considerado, apresenta-se provisoriamente como

3 Hjelmslev (2009) dá ao termo "sentido" a mesma acepção de "matéria", tanto que emprega indistintamente ambas as palavras. Tais definições são estruturadas a partir das relações expressão/conteúdo e forma/substância cunhadas pelo linguista dinamarquês, segundo as quais o sentido se manifesta a partir de formas (ou "suportes"), que nada mais são do que recortes e contornos efetuados por uma semiótica qualquer aos seus elementos constitutivos, isto é, às substâncias. Assim, dizem Greimas e Courtés (2008, p. 457), "O termo substância é em seguida utilizado para designar o sentido enquanto algo assumido por uma semiótica, o que permite distinguir então a substância do conteúdo da substância da expressão". 
uma massa amorfa, uma grandeza não analisada, definida apenas por suas funções externas, isto é, por sua função contraída com cada uma das proposições citadas. [...] o sentido é ordenado, articulado, formado de modo diferente segundo as diferentes línguas (HJELMSLEV, 2009, p. 56).

Logo, a tradução entre línguas ou interlingual (cf. JAKOBSON, 1977) ocorreria mediante uma transposição sistêmica, uma tarefa fundamentada especialmente na reconstrução textual. Isto é, a despeito das diferenças entre ambas as línguas, os sentidos ${ }^{4}$ compartilhados entre a língua de origem (em que foi escrito o texto original) e a língua-alvo (para a qual o texto será traduzido) permitiriam a reescritura do texto e a transposição desses sentidos. Obviamente, esse processo não se dará de modo absoluto ou integral, levando-se em conta as especificidades lexicais, fonológicas e sintáticosemânticas de cada língua, mas daí decorrerá um processo de atualização desse conteúdo significante, gerando-se assim um novo texto, mas que se mantém correspondente ao original no que tange ao sentido. A tradução, por esse entendimento, também se pauta por uma função semiótica.

Jakobson (1977) enfatiza com precisão o papel do tradutor como um recriador, um agente reconstrutor dos sentidos de um texto produzido em uma dada língua, operando em outra:

Ao traduzir de uma língua para outra, substituem-se mensagens em uma das línguas, não por unidades de código separadas, mas por mensagens inteiras de outra língua. Tal tradução é uma forma de discurso indireto: o tradutor recodifica e transmite uma mensagem recebida de outra fonte.

4 Aqui, o termo é empregado por Jakobson como sendo um "quase sinônimo" de significação, diferenciando-se da abordagem hjelmsleviana. 
Assim, a tradução envolve duas mensagens equivalentes em dois códigos diferentes (JAKOBSON, 1977, p. 64).

Ainda que as diferenças nos processos gramaticais entre as línguas envolvidas sejam significativas ou mesmo profundas, isso não se revela um impeditivo para o processo tradutório, pois o elemento conceitual (sentido) pode ser transposto para a língua-alvo, mesmo sendo necessárias adaptações. 0 principal, nesse processo, não é meramente o sistema gramatical de cada língua, mas as representações de aspectos de experiências (culturais, sociais, individuais, etc.) que cada língua traz - e isso não se dá de maneira fragmentada ou isolada, limitada a traduções de palavras ou sintagmas, mas ocorre sempre no nível da totalidade, isto é, do texto.

0 trabalho de Bassnnett (2005), embora ligado a uma abordagem distinta daquela adotada neste artigo ${ }^{5}$, revela-se pertinente aos objetivos aqui propostos por apresentar e debater criticamente alguns enfoques consagrados nos estudos de tradução contemporâneos, sobretudo os trabalhos de Nida e Taber (1982) e Catford (1980). Ao longo de suas análises, a pesquisadora aponta como problemáticos alguns conceitos usados pelos autores, tais como os de transferência e os de equivalência. No primeiro caso, o modelo explicativo de Nida e Taber dá a entender que o processo de transferência ocor-

5 Ressalta-se que o trabalho de Bassnnett (2005) filia-se aos Estudos Culturais e à perspectiva pós-estruturalista, sendo esta última uma contraposição ao paradigma estruturalista. Para este artigo, é interessante apenas frisar as considerações feitas pela autora acerca de aspectos específicos do fazer tradutório que, posteriormente, foram relidos e reinterpretados conforme o enquadre teórico aqui estabelecido. Mediante as operações da sintaxe discursiva, as quais incluem as operações enunciativas dentro do modelo teórico da semiótica, procura-se ressaltar o papel fundamental de cada um dos agentes constitutivos do sujeito da enunciação (enunciador e enunciatário, além de seus desdobramentos) na construção dos sentidos, sem dar primazia nem ao sistema linguístico (como ocorre nos estudos estruturalistas tradicionais), nem ao sujeito - que, acredita-se, é supervalorizado pelos pós-estruturalistas. 
re de maneira linear, como se a substituição de itens lexicais, sintáticos e semânticos ocorresse de maneira plena - o que de fato não acontece. A substituição de materiais pertinentes à estrutura da língua, como também preconiza Catford (1980), não se dá integralmente levando-se em conta apenas os aspectos formais, mas também elementos pragmáticos e culturais que justificam o emprego de um determinado item lexical, sintagmático ou textual.

No segundo caso, o princípio da equivalência tem por fundamento um núcleo semântico comum entre as duas línguas, e cujo objetivo do tradutor é preservá-lo, substituindo os itens lexicogramaticais da língua fonte por outros que, culturalmente, funcionem de modo semelhante na língua alvo. Trata-se de uma escolha não apenas semântica, mas pragmática. Entretanto, as possíveis diferenças interlinguais podem acarretar em um afastamento considerável de ambas, exigindo do tradutor um esforço adicional para a manutenção desse "núcleo sêmico comum", o que pode gerar, ao longo desse processo, o que Bassnnett (2005) define como perdas e ganhos. Por esse viés, não se deve perseguir a igualdade na tradução, mas compreender que se trata de uma relação dialógica entre dois sistemas linguísticos e, mais do que isso, duas culturas distintas que se entrecruzam em uma totalidade de sentido (texto). Logo, durante o processo tradutório, será inevitável a ocorrência de perdas (decorrentes de supressões e alterações durante a textualização, operando no nível figurativo mediante condensação), mas também é possível ocorrer ganhos - acréscimos, esclarecimentos e outros elementos que, mediante expansão, enriquecem o texto traduzido.

Mittmann (2003), nesse aspecto em particular, mos- 
tra-se convergente com algumas posições aqui assumidas, especialmente no que tange aos papéis do tradutor e em uma compreensão da tradução como um processo, em vez de atentar-se somente ao produto desse processo (o texto traduzido). Por um lado, a autora critica as abordagens tradicionais por conferirem ao tradutor um papel meramente instrumental, isto é, de um recodificador textual que deve se manter invisível ao longo do processo em nome de uma pretensa fidelidade ao original (esse assunto será discutido mais adiante) - trata-se, portanto, de uma concepção passiva do sujeito tradutor, o qual se subordina aos agentes envolvidos no processo tradutório (autor do original, texto original e leitor do original). Por outro, referindo-se às abordagens mais atuais (incluindo-se aquelas sob uma perspectiva pós-estruturalista), Mittmann (2003) destaca um papel do tradutor como agente interpretativo, responsável não simplesmente pela retransmissão e transposição de sentidos de um original qualquer, mas em atuar como um copartícipe na construção dos sentidos (fazendo o papel de atualizá-los) - e cuja tarefa será ainda completada pelo leitor, a etapa final desse processo que envolve vários fazeres.

É importante nessa leitura de Mittmann (2003), assim como o fazemos em nosso trabalho, que não nos referimos aos seres ontológicos, aos autores, tradutores e leitores de "carne e osso", mas a instâncias construídas no discurso, levando-se em conta que, ao se entender a tradução como um processo, ela é compreendida como um ato enunciativo, de colocar em funcio-

60 trabalho de Mittmann (2003), a despeito de apresentar pontos de contato com posições endossadas por este artigo, insere-se no quadro teórico da análise do discurso de linha francesa (AD), influenciada sobretudo pelos trabalhos dos filósofos franceses Michel Pêcheux e Michel Foucault. Por isso, foi necessário ressignificar esses conteúdos convergentes para incluí-los no enquadramento adotado neste trabalho, da mesma forma como foi feito com as contribuições de Bassnnett (2005). 
namento determinadas potencialidades linguísticas e manifestá-las sob a forma de um texto, tendo por base um original e como meta uma tradução. Assim, não é pertinente discutir os procedimentos tradutórios isoladamente, como se essa atividade se resumisse a mera substituição ou rearranjo de elementos léxico-gramaticais, mas é compreender a tradução como uma atividade de reconstrução de sentidos e que vê o texto, sua matéria-prima, como uma totalidade a ser considerada.

\section{Semiótica e Tradução}

Os primeiros estágios da proposta semiótica remontam ao projeto de semântica estrutural (GREIMAS, 1973), segundo o qual se buscava uma teoria geral da significação das línguas naturais, apropriando-se fundamentalmente na linguística saussuriana, nas contribuições de Hjelmslev (2009), na metodologia de Propp (1984) para análise de contos maravilhosos russos e, mais discretamente, na fenomenologia da percepção.

A despeito das grandes mudanças sofridas por esse arcabouço teórico e pelo abandono de alguns pressupostos iniciais - como a fundamentação do modelo analítico sob o modelo fonológico, algo que se mostrou inviável com o tempo - um dos pilares do projeto greimasiano se mantém intacto, como bem observa Bertrand (2003), que é estudar a significação de um objeto qualquer em sua totalidade. Isto significa que pouco importa para a semiótica francesa apreender os sentidos dos elementos em sua individualidade, pois qualquer traço semântico que estes venham a carregar pode ser atualizado se inserido em uma totalidade maior (o texto). Portanto, os sentidos criados dentro dessa totalidade se manifestam a partir da junção entre os significados consagrados pelo uso, em sua maioria já lexicalizados (núcleo sêmico), e 
aqueles oriundos da relação dos termos entre si, na totalidade do texto, e fortemente influenciados pelas coerções de gênero e da cultura (sema contextual ou classema).

Assim, ainda que se reconheça a existência e o valor dos signos linguísticos, formados pela associação entre uma expressão e um conteúdo em suas respectivas formas e substâncias, eles só ganham relevância para a semiótica ao fazerem parte de um texto, pois é ali que seus sentidos serão atualizados e integrar-se-ão a um todo.

Para os estudos da tradução, a perspectiva semiótica mostra-se pertinente por não considerar como objeto dessa primeira área o estudo de palavras e sintagmas isoladamente, mas desses elementos quando pertencentes a um texto. Logo, é o texto que deve ser o alvo dos estudos da tradução, levando-se em consideração que os sentidos em uma língua não se transpõem a outra de maneira individualizada, como se fosse possível haver uma equivalência plena entre as palavras e frases de línguas distintas entre si.

Por essa visão, o sentido, decorrente de uma função semiótica, se cria a partir da articulação entre os planos de expressão e de conteúdo, cada qual com suas formas e substâncias. Os aspectos conceituais e abstratos, bem como seu material constitutivo, são recortados, ajustados e organizados de maneiras variadas conforme o sistema linguístico em questão e mediante a interveniência da cultura de seu respectivo povo falante. É desse modo que as línguas significam (HJELMSLEV, 2009).

Um processo de tradução viável pela perspectiva semiótica precisa ocorrer, conforme os parâmetros de Jakobson (1977) e Hjelmslev (2009) no nível do texto, e não no da palavra. Isso porque a semiótica, concebida por Greimas (1975) e Greimas e Courtés (2008) como uma teoria geral da signi- 
ficação, elege o texto como a sua grandeza mínima, seu objeto principal de estudo, o qual se constitui por um feixe de relações estruturantes que se dão do ponto de vista lógicoconceitual (estruturas semionarrativas) quanto na disposição de seus elementos mais concretos (estruturas discursivas). Trata-se de um objeto que precisa ser considerado em sua totalidade em qualquer estudo sob o viés da semiótica francesa.

No Dicionário de semiótica, Greimas e Courtés (2008, p. 508-509) definem a tradução como uma "atividade cognitiva que opera a passagem de um enunciado dado em outro enunciado considerado como equivalente". Tal definição, apesar de muito breve, aponta alguns caminhos de interpretação desse conceito segundo o viés da semiótica discursiva. Os autores consideram esse procedimento uma operação de mão dupla. Como o sentido, segundo o pensamento semiótico, está presente em todas as línguas naturais e é compartilhado por todos, a despeito das diferenças formais e substanciais entre elas, a tradução, mais do que mera transposição de elementos entre línguas, é também um processo significante já que, segundo os autores, “'falar do sentido' é ao mesmo tempo traduzir e produzir significação".

Greimas e Courtés (2008) destacam também uma peculiaridade fundamental das línguas naturais, que é servir como "língua de chegada" para outros sistemas semióticos. Isso significa que seria perfeitamente possível traduzir uma totalidade significativa produzida em um sistema semiótico qualquer (como uma pintura, uma fotografia, etc.) para uma língua natural, preservando assim a essência do sentido — tal acepção coaduna com o conceito de tradução intersemiótica desenvolvido por Jakobson (1977), quando essa operação envolve sistemas semióticos distintos. Além disso, é destacada também a propriedade das línguas naturais em dispor dos materiais 
necessários para construírem metalinguagens, isto é, para falarem delas próprias - mediante operações parafrásticas ou, como diz Jakobson, via uma tradução interlingual.

Greimas e Courtés (2008), contudo, advertem que cada objeto construído sob um determinado sistema semiótico é uma totalidade significante independente, que por si só é dotada e capaz de comunicar seu sentido. Tais objetos não dependem da verbalização para se tornarem significativos como se as línguas possuíssem cargas significativas a priori que "complementariam" o sentido expresso por outras semióticas. Mas é fato que, independente do sistema semiótico usado, não há sentidos dados, subjacentes em um determinado elemento dessa cadeia, mas eles significam estando em relação, integrados a um todo. 0 sentido, para a semiótica, é construído mediante essas relações entre os elementos de uma determinada totalidade significante.

Enfim, para um enquadramento adequado do processo tradutório sob o viés semiótico - levando-se em conta a definição de Greimas e Courtés (2008), o mais pertinente é concebê-la como um procedimento que mobiliza as possibilidades estruturais e semânticas de uma língua e a retextualizam em outra, isto é, é um fazer que ocorre no nível da enunciação. Tal como diz Benveniste (2005), a enunciação é a instância mediadora entre o sistema e o uso - a língua e suas potencialidades, por um lado, e sua operacionalização mediante a fala (transformando-a em enunciados), por outro.

Tomando por base essas reflexões, pontuadas pelos estudos de Fiorin (2005, 2010), a semiótica irá integrar a enunciação em seu quadro teórico e lhe conferir um papel fundamental na geração do sentido. Ela não se limita apenas a uma apropriação individual da língua pelo indivíduo, mas pela instauração no discurso das categorias de pessoa, espaço 
e tempo que irão regulá-lo. Assim, a enunciação estabelece as categorias referenciais que irão estruturar o nível discursivo, a ser manifestado pela articulação de temas e figuras, mas pelo estabelecimento dos sujeitos, dos responsáveis pelo ato de dizer (eu) e para o qual ele é destinado (tu) — é a instauração, portanto, das relações de identidade e alteridade no discurso, isto é, do sujeito da enunciação.

Pode-se dizer, portanto, que a prática tradutória se configura igualmente como uma práxis enunciativa, tal como dito por Fiorin (2010), Fontanille e Zilberberg (2001) e Bertrand (2003). Isso se dá em decorrência de um caráter dicotômico de toda manifestação linguística (enunciado), gerada a partir de um ato enunciativo, que ora engloba elementos estipulados pelo sistema (langue), ora outros determinados pelo uso (parole). Ao se produzir novos enunciados, o indivíduo recorre a estruturas e elementos já ditos em momentos anteriores, constituídos por atos enunciativos de outrora (caráter histórico da enunciação, que pode ser associado sem temor ao conceito de dialogismo, cunhado pelo círculo de Bakhtin). Entretanto, tais elementos podem assumir acepções variadas, ou mesmo inovadoras, a partir de um processo de atualização conforme as condições da enunciação. Esses novos usos, empregados por cada indivíduo ou grupo de indivíduos, podem assumir um caráter socializado, sendo empregados por outros grupos sociais e, assim, incorporados à cultura, ou serem rejeitados, ficando restritos a usos particularizados - ou mesmo fadados ao desaparecimento.

Ao trazer essas discussões para o bojo da tradução, é possível estabelecer algumas considerações acerca do fazer tradutório. Para fundamentar e esclarecer melhor esses posicionamentos recorre-se ao estudo de Aubert (1993) — ainda que com algumas modificações. No que tange aos papéis 
actanciais que regulam esse ato enunciativo, manifestados no discurso, podemos identificar ao menos cinco deles: 1) um enunciador-autor, instância responsável pelo enunciado (texto) de origem; 2) um enunciatário-leitor original, criado como uma projeção (simulacro) de um eventual leitor do texto original, a quem o enunciador-autor se dirige; 3 ) um enunciatário-tradutor, que se insere no processo como receptor do texto-fonte ${ }^{7}$, guardando ou não alguma correspondência com o perfil do enunciatário-leitor original; 4) um enunciador-tradutor, que assume o papel de reconstruir o enunciado original em uma língua-alvo qualquer e 5) um enunciatário-leitor da tradução, construído no discurso do texto traduzido, e que procura ser próximo (embora jamais idêntico, devido a fatores linguísticos, sociais e culturais distintos) do enunciatário original.

Apresentados os actantes, passa-se agora a discorrer sobre os fazeres pertinentes ao ato de tradução. Em semiótica, para que haja uma transformação nos eventos que constituem o nível semionarrativo, é preciso que os responsáveis por tal sejam modalizados, isto é, sejam investidos dos predicados necessários para se garantir a dinâmica do percurso gerativo de sentido, mecanismo teórico-metodológico que estuda como o sentido em qualquer objeto semiótico é engendrado. A partir desses predicados, o tradutor (na condição de papel actancial), será capaz ou não de efetuar as transformações necessárias tendo em vista o cumprimento de um dado objetivo, que no caso seria uma tradução bem-sucedida, efetuando uma relação conjuntiva com o seu objeto-valor, ou disjuntiva caso fracasse em seu intento.

70 texto-fonte é entendido como o original a ser traduzido, enquanto o texto-meta (ou texto-alvo) diz respeito ao texto obtido via tradução. Os mesmos conceitos são aplicáveis às línguas e às culturas pertinentes a cada tipo de texto. 
Quanto às modalidades, julgamos apresentá-las em cotejo com as impressões dos teóricos de tradução apresentados neste trabalho, sobretudo Aubert (1993). O tradutor, perante o seu objeto-valor, pode assumir duas posturas majoritárias - não necessariamente excludentes ou estanques. A primeira, que chamaremos de pró-texto ou passiva, volta-se a preservar a "fidelidade" ao texto original, evitando assim intervenções mais profundas ou radicais por parte do enunciador-tradutor. É uma posição, segundo Aubert (1993), que crê na possibilidade de manutenção integral da mensagem original, a despeito da série de fatores intervenientes no ato de traduzir. A outra postura, chamada neste trabalho de prótradutor ou ativa, valoriza e endossa o papel desse sujeitotradutor na reconstrução de um dado enunciado em uma língua de destino, tendo-se a ciência de que uma recriação ipsis litteris do original é impossível e, por isso, o tradutor precisa mobilizar seus aparatos cognitivos e socioculturais para solucionar eventuais incompatibilidades entre os sistemas semióticos envolvidos - trata-se, portanto, de uma postura que valoriza a liberdade do tradutor, em vez de perseguir uma fidelidade aparentemente inatingível.

Em termos semióticos, o sujeito tradutor em uma posição pró-textual assume a fidelidade como uma meta a ser buscada - isto é, um dever-fazer - e uma postura a ser adotada (dever-ser). Esses dois predicados assumiriam a faceta de um contrato de veridicção, fundamentado na crença de que o tradutor é capaz de preservar a integridade de um original qualquer, e na expectativa de que um texto traduzido mediante esses parâmetros manterá os valores do texto-fonte.

Para resumir essa postura de subordinação ao original, característica da concepção pró-texto, segue abaixo uma citação de Silveira (2004, p. 21): 
Quanto a traduções, a editora exige, de seus tradutores, três coisas: primeiro, fidelidade; segundo, fidelidade; e, terceiro, ainda fidelidade. Depois é que entram todas as demais qualidades que se requer de um bom tradutor. Antes de mais nada, o tradutor tem de adotar uma atitude de humildade diante do original que tem à sua frente. Deve lembrar-se, sempre, de que não é autor, nem coautor da obra. A sua tarefa é simplesmente esta: passar para a sua língua, da maneira mais fiel possível, tudo o que está escrito no original. Não tem o direito de alterar, modificar, omitir ou acrescentar coisa alguma. 0 livro, na tradução, tem de ser o que o livro seria se o autor dispusesse de algum meio mágico que lhe permitisse escrevê-lo, simultaneamente, identicamente, em dois idiomas.

Por outro lado, uma postura pró-tradutor está mais de acordo com os posicionamentos de Mittmann (2003) e Bassnnett (2005). 0 que modalizaria a prática tradutória não seria uma obrigação de se manter uma fidelidade canina ao original, mas a possibilidade de preservar o sentido geral, a ideia e, se possível, os recursos estilísticos como forma de assegurar, nas palavras de Bassnnett (2005) o "sabor" do texto. Tratase, nesse caso, de uma relação que envolve um querer-fazer/ querer-ser e um poder-fazer/poder-ser, que reconhece e valoriza as competências do sujeito-tradutor ao estabelecer um diálogo com o texto-fonte, e as quais serão mobilizadas para que os aspectos identitários e significantes do original sejam mantidos, mas dando-lhe a liberdade de adaptá-lo se isso for necessário, levando-se em conta as peculiaridades dos sistemas linguísticos em uso e, sobretudo, as características linguísticas, cognitivas e socioculturais do enunciatário da tradução - e suas aproximações com o enunciatário do texto-fonte. Contudo, essa posição que favorece o tradutor não 
coaduna com uma liberdade excessiva, como bem aponta Bassnnett (2005), que nesse caso inferioriza e subjuga o texto original, sua língua e cultura, em favor dos sistemas linguísticos e socioculturais do texto traduzido.

Diante do exposto, percebemos que a tradução como práxis enunciativa pode assumir uma faceta mais conservadora, balizada por uma busca de maior fidelidade possível ao texto-fonte, ou um lado mais libertário, em que o sujeito-tradutor tem margem para se livrar das eventuais amarras do original e buscar saídas próprias para reconstruir os sentidos deste último no texto traduzido. Esses procedimentos, contudo, não podem ser entendidos sob uma perspectiva extremista, mas como parâmetros possíveis para a compreensão do fazer tradutório e quais as tendências que se podem empregar - se aquelas mais apegadas à fidelidade estrutural ou as que permitem maior flexibilidade na tradução.

As gradações que podem assumir o processo tradutório e seu resultado final estão diretamente relacionadas, além dos fatores já supracitados, com o gênero em que se insere o texto-fonte (organização retórico-textual, finalidade, registro...), que podem mobilizar o tradutor a aproximar-se ou afastar-se mais do original. É o que acontece, por exemplo, com os textos técnico-científicos, cujas características de gênero exigem procedimentos e condutas específicas por parte do tradutor. Isso será objeto de discussão na seção seguinte.

\section{Estudo de aplicação em Traduções Técnico- Científicas}

Após a apresentação da fundamentação teórica deste trabalho, a próxima etapa será a de aplicar os conceitos analisados a um corpus composto por quatro resumos e seus res- 
pectivos abstracts de artigos científicos da área de psicologia, obtidos de revistas especializadas bem avaliadas pela CAPES - mais especificamente, Qualis A1 e A2, que já conferem status internacional à publicação.

A escolha desse corpus em particular não atende apenas a um critério pessoal, pertinente à área de atuação profissional do autor. Pensou-se em usar resumos e abstracts de artigos científicos por corresponder a um objeto com uma totalidade de sentido definida, que permite o seu cotejo e análise sob a perspectiva semiótica - cujo objetivo justamente é analisar as estruturas significantes dos seus respectivos objetos - em conjunto com as teorias da tradução, de maneira a verificar aspectos como a equivalência entre termos, organização sintático-semântica do texto, entre outros elementos. Por fim, pelo caráter exíguo deste trabalho, mostra-se conveniente recorrer a um corpus enxuto, mas significativo e viável para a aplicação teórica pretendida.

Antes de se começar esse estágio do trabalho, é válido situar a presente discussão em um âmbito mais específico, pertinente à tradução técnico-científica. Nessa seara, lembram Polchlopek e Aio (2009), a preocupação desse tipo de texto é restringir os campos semânticos possíveis de leitura com vistas a um percurso traçado pelo enunciador — ou, em termos semióticos, trata-se de um texto monoisotópico - mediante o emprego de terminologias específicas para descrever fenômenos e conceitos. Esses termos, próprios das linguagens especializadas, são constituídos de elementos pertinentes à área do saber a que se vinculam (assumindo, assim, o caráter de sema contextual ou classema, cf. Greimas (1973) e Bertrand (2003)) e de outros já consagrados pela cultura e registrados no léxico da língua em questão (caráter de lexema).

É muito importante frisar que essas autoras, basean- 
do-se também em Aubert (2001), situam a tradução técnico-científica tanto no aspecto do sistema quanto do uso, por mobilizar um "conjunto de marcas sintáticas, lexicais, estilísticas e discursivas que tipificam o código linguístico dentro de um ambiente de interação social especifico" (AUBERT, 2001, p. 24-25). Logo, o emprego terminológico em um texto especializado depende de um ato enunciativo, o qual envolve a atualização dos elementos pertinentes ao sistema linguístico e sua realização sob forma de texto, levando-se em conta as finalidades do enunciador, as coerções de gênero e o simulacro de seu enunciatário.

A tradução técnico-científica, sob esse viés, conduz a uma práxis enunciativa voltada essencialmente para uma orientação mais conservadora, em que se procura atingir determinados graus de precisão, correção, impessoalidade e objetividade no produto final - características próprias do discurso científico de modo geral. 0 enunciador-tradutor assumiria, desse modo, uma conduta próxima a do enunciador do texto original, em que se busca preservar o caráter monoisotópico e a essência lógico-conceitual do texto-fonte.

Entretanto, mesmo nessa seara, perseguir uma fidelidade obstinada mostra-se praticamente impossível, e obriga o tradutor a cometer desvios, como bem coloca Aubert (1987, p. 186).

O desvio, no processo tradutório, é inescapável. Para que se preserve a essência do original, isto é, o sentido, podem ser necessários ajustes léxico-gramaticais, semânticos e sintáticos para que seja possível comunicar ao enunciatário a "mensagem" (isto é, o sentido). "Traduzir é desviar; sem desvio não há tradução, mas tão somente cópia, mais ou menos imperfeita. A fidelidade à mensagem exige, portanto, uma infidelidade à forma, que será tanto menor quanto mais sen- 
síveis as divergências léxico-gramaticais, sociolinguísticas e antropoculturais entre os universos textuais de partida e de chegada do ato tradutório (AUBERT, 1987, p. 186).

Para esta etapa, além dos conceitos já apresentados, também serão utilizados os procedimentos técnicos da tradução consagrados pelos teóricos Jean-Paul Vinay e Jean Darbelnet, atualizados por Aubert (1998) e Barbosa (2007). Mais do que critérios meramente instrumentais, esses procedimentos revelam os posicionamentos próprios do tradutor como sujeito da enunciação e as concepções linguísticas adotadas no fazer tradutório, que podem indicar, por exemplo, uma maior preocupação com a fidelidade ao original ou, ao contrário, em gestos de libertação (ou mesmo de rebeldia) perante as coerções do sistema linguístico.

Nos casos em tela, percebe-se nos textos analisados que existe uma maior tendência para o uso da tradução literal como o principal procedimento de tradução empregado. Segundo Aubert (1998) e Barbosa (2007), a tradução literal é aquela que visa à preservação das estruturas lexicogramaticais e semânticas do original - por isso, também é chamada de tradução palavra por palavra. Para ilustrar, seguem alguns excertos de originais e suas respectivas traduções, para fins de cotejo.

TF: This paper seeks to retrieve Marx's ideas about the development of psychology. It offers historical perspectives on different attempts to create a Marxist psychology that shed light on its scope and trajectory. According to Marx, concrete social and material real life play a key role in the development of human psychological functions. [...] Marxist psychology is the study of the social individual within social relations of production. In a Marxist sense, the emphasis is placed on production, both material and social as the es- 
sence of social relations. Hence, psychology cannot be dealt with in an abstract, private and individual manner as the capitalist mode of production would want, but must be seen in terms of the social individual that is formed, structured, and shaped within the social relations of a production framework. In this context, the social production of the individual (as developed in Marx's Die Grundrisse) signifies social relations between people connected with concrete common real social conditions and material production.

TM: Este artigo busca recuperar as ideias de Marx sobre o desenvolvimento da Psicologia. Apresenta abordagens históricas sobre as diversas tentativas de criar uma psicologia marxista que elucidam sobre a sua abrangência e trajetória. Segundo Marx, a vida real material e a vida social concreta desempenham um papel-chave no desenvolvimento das funções psicológicas humanas. [...] A psicologia marxista é o estudo do indivíduo social dentro das relações sociais de produção. Em um sentido marxista, a ênfase é na produção, tanto material quanto social, como a essência das relações sociais. Portanto, não se pode tratar a Psicologia de forma abstrata, privada e individual como o modo capitalista de produção gostaria, mas ela deverá ser considerada em relação ao indivíduo social que é formado, estruturado e moldado dentro das relações sociais de uma estrutura de produção. Neste contexto, a produção social do indivíduo (como elaborada em Die Grundrisse do Marx) significa as relações sociais entre pessoas conectadas às condições sociais reais e comuns e a produção material (ELHAMMOUMI, 2012, p. 3).

TF: In this article, we briefly review the antecedents of this approach and explore its core concepts, indicating their roots and the precise way in which they are applied to developmental analyses today. We also examine the implications of the systems approach for developmental investigation, and its challenges.

TM: Neste artigo, nós brevemente revisamos os antecedentes dessa abordagem e exploramos seus conceitos básicos 
(centrais), indicando suas origens e caminhos precisos nos quais eles são aplicados na análise do desenvolvimento nos dias de hoje. Nós também examinamos as implicações da visão sistêmica para investigação do desenvolvimento e seus desafios (TINAJERO; PARAMO, 2012, p. 457).

Os exemplos acima ilustram com clareza uma conduta do enunciador-tradutor em equiparar as estruturas léxicogramaticais de ambos os textos, inclusive no que tange às escolhas lexicais. Isso se dá mediante uma perspectiva tradutória conservadora, em que esse gesto enunciativo tenderia a conservar a essência do sentido dos termos e conceitos técnico-científicos a partir da literalidade, de modo que é possível estabelecer um paralelismo entre texto-fonte e texto-meta.

Essa postura do enunciador-tradutor coaduna também com as considerações de Greimas (1975) acerca da linguagem científica, a qual é tratada como uma instância mediadora entre os fenômenos cognoscíveis, pertencentes ao mundo natural e apreensíveis pelos sentidos, e as representações lógico-conceituais destes construídas pela razão. A organicidade e sistematização dessas representações do cognoscível com seus respectivos objetos de conhecimento permitem a construção do saber científico e sua configuração em um sistema semiótico capaz de descrevê-lo e disseminá-lo com a precisão e especificidade necessárias para tal - mediante a criação de metalinguagens próprias e, posteriormente, das terminologias.

Portanto, a partir de uma práxis enunciativa conservadora, o enunciador da tradução assume predicados modais orientados pela prescrição (dever-ser) e pela obediência (não poder não fazer), cujo fim é a preservação da "fidelidade" do original e, sobretudo, do conhecimento cientifico subjacente a este. Ademais, a tradução sob esse aspecto deve também conservar o caráter veridictório do texto científico, 
que tem por princípio divulgar um saber, uma "verdade", ou melhor, uma impressão de verdade (parecer-ser).

Essa postura tem se mantido, segundo os mesmos princípios, na tradução das terminologias - como nos casos de Gauer et al. (2013) e Campos, Carlotto e Maroco (2013), que recorreram à literalidade ao traduzirem o nome de um instrumento de pesquisa (Centrality of Event Scale/Escala de Centralidade de Evento no primeiro caso e Copenhagen Burnout Inventory for College Students/Inventário de Burnout de Copenhagen para Estudantes, no segundo, apesar de este último omitir, na tradução, o adjetivo "college/universitários", que consideramos um dado relevante e que deveria ser preservado no nome em português).

Contudo, verifica-se no mesmo corpus - ainda que em menor grau - outros procedimentos adotados nas traduções, com efeitos variáveis. Recorreu-se a ajustamentos sintáticos na língua-meta (transposição) e até mesmo a modulações, em que há uma considerável alteração na tessitura semântica, preservando-se apenas o "efeito geral de sentido" (AUBERT, 1998, p. 108). Seguem abaixo os excertos:

TF: Developmental Psychology seems to have come to an unifying theoretical framework which may make feasible to overcome the fragmentation $\underline{\text { so frequently referred to within }}$ the discipline.

TM: A Psicologia do Desenvolvimento parece ter chegado a uma estrutura teórica de trabalho que pode tornar possível vencer a barreira da fragmentação, frequentemente referida na disciplina (TINAJERO; PARAMO, 2012, p. 457, grifo nosso).

TF: A stressful or traumatic event may become a central reference point in the organization of long-term memory, influencing the meaning of other experiences. The Centrality of Event Scale (CES) is an instrument in which participants recall the 
most traumatic event of their life and endorse 20 items. The CES was translated, adapted and validated for the Brazilian context in a sample of 195 undergraduates (75.8\% women). TM: Um evento estressor ou traumático pode tornar-se um ponto de referência central na organização da memória de longo prazo, influenciando a significação das demais experiências. A Escala de Centralidade de Evento (ECE) é um instrumento em que o sujeito recorda o evento mais traumático de sua vida e endossa 20 itens respectivos. A ECE foi traduzida, adaptada e validada mediante aplicação em 195 estudantes universitários (75,8\% mulheres) (GAUER et al., 2013, p. 98, grifo nosso).

TF: The objective of this study was to evaluate the psychometric properties of an assessment instrument on teachers' perceptions regarding the development of socio-emotional skills. Results revealed a consistent four-factor structure...

TM: 0 objectivo deste estudo foi avaliar as características psicométricas de um instrumento de avaliação das percepções dos professores acerca das suas necessidades na promoção das competências sociais e emocionais. Os resultados revelaram uma estrutura de quatro factores... (MOREIRA et al., 2013, p. 67, grifo nosso).

Nos fragmentos acima, percebem-se alguns ajustamentos voltados ao acréscimo ou a supressão de elementos sintagmáticos no texto-meta. Esses procedimentos obedecem, respectivamente, aos princípios de expansão e condensação já apresentados por Greimas (1973) e Bertrand (2003), em que, durante a textualização do texto traduzido, servem para adequar o enunciado às regras de funcionamento do sistema linguístico em questão, as quais não obedecem apenas princípios sintáticos e semânticos, (como no caso dos adjetivos, que no inglês podem ser formados pela junção, mediante hifenização, de um elemento verbal e outro não verbal - sofrendo uma 
condensação em relação ao português) mas também estilísticos. No texto em português, o uso mais frequente de marcadores discursivos não se mostrou tão relevante para expressar o sentido desejado, enquanto que na versão em inglês, a inclusão dos advérbios so (tão) e within (dentro de) revelouse pertinente para conferir maior precisão ao enunciado e às informações nele contidas. Esse é um exemplo possível de transposição textual mediante expansão ou condensação e, portanto, exigiu do enunciador-tradutor um certo grau, ainda que bastante restrito, de liberdade e possibilidade em seu fazer para que se efetuassem tais modificações, tendo em vista a manutenção da essência do sentido do enunciado.

Em um dos casos, contudo, a omissão não parece justificada e acarretou problemas na tradução. No original, Gauer et al. (2013) informam, para fins de detalhamento, o país de origem dos participantes de sua pesquisa (Brazilian/brasileiros), mas esse elemento foi suprimido da tradução. Não se encontrou uma explicação plausível dessa omissão, pois tanto o resumo em português quanto o abstract compartilham o mesmo espaço e são voltados ao mesmo público-alvo. A informação da nacionalidade seria redundante caso o artigo tivesse uma circulação restrita ao âmbito local, mas por se tratar de um texto publicado em periódico com repercussão internacional, entende-se que a supressão da nacionalidade dos participantes na tradução pareceu equivocada. Caso similar ocorre, embora mais grave, ao se omitir no texto em português o fato de a Escala de Centralidade de Evento ter sido adaptada ao contexto brasileiro - uma informação central na pesquisa de Gauer et al. (2013) que, acreditase, deveria ter sido mantida, pois sua omissão pode causar problemas na compreensão do texto pelo enunciatário. Esse último caso, portanto, foi o de um exercício malsucedido de liberdade e possibilidade do enunciador-tradutor. 
Em menor quantidade, mas presentes em alguns resumos, foram encontrados índices de modulação, considerados no caso em estudo o grau máximo de intervenção do tradutor na estrutura semântica do original (apenas não maior que o da adaptação, mas esta não se aplica ao nosso estudo), sendo preservada basicamente a "ideia geral" - como pode ser visto nos excertos logo abaixo:

TF: The Copenhagen Burnout Inventory for college students (CBI-S) was adapted to the Portuguese language and its reliability and validity studied in a sample of both Brazilian ( $n=958)$ and Portuguese $(n=556)$ college students. The confirmatory factor analysis of the CBI-S showed good fit but two items were removed since they lack individual reliability $(\lambda<.50)$. The new structure showed a good fit on $2 / 3$ of the total sample and was invariant in the other $1 / 3$ of the sample. The CBI-S factor weights were not invariant in the Brazilian and Portuguese samples. Internal consistency as well as convergent, discriminant and concurrent validity were good. The Portuguese CBI-S showed adequate reliability and validity but did not show cross-cultural validity. TM: Realizou-se adaptação cultural do Inventário de Burnout de Copenhagen para estudantes (CBI-S) em português e estimou-se sua confiabilidade e validade. 0 CBI-S foi preenchido por 958 estudantes universitários brasileiros e 556 portugueses. 0 modelo fatorial original apresentou bom ajustamento entretanto, foram removidos dois itens com confiabilidade individual baixa $(\lambda<0,5)$. A nova estrutura apresentou bom ajustamento a $2 / 3$ da amostra total sendo invariante no $1 / 3$ restante da amostra original. Verificou-se adequada consistência interna e validade convergente, discriminante e concorrente. Os pesos fatoriais do CBI-S não foram invariantes nas amostras de Brasil e Portugal. $\underline{\mathrm{O} C B I-S}$ apresentou adequada confiabilidade e validade entretanto, verificou-se ausência de estabilidade transcultural (CAMPOS; CARLOTTO; MAROCO, 2013, p. 87, grifo nosso). 
Logo no início dos resumos de Campos, Carlotto e Maroco (2013), percebem-se nítidas diferenças na ordenação sintática e semântica quando se fez uso, no texto em português, da voz passiva sintética ("Realizou-se adaptação cultural do Inventário de Burnout de Copenhagen para estudantes (CBI-S) em português e estimou-se sua confiabilidade e validade") diferentemente do efetuado no original ("The Copenhagen Burnout Inventory for college students (CBI-S) was adapted to the Portuguese language...") - uma voz passiva analítica. 0 efeito imediato desse rearranjo foi enfatizar o fato abordado no artigo, que é a adaptação do instrumento em questão (CBI-S) para a língua portuguesa, pois este funciona como o sujeito desta oração. Já em inglês, a ênfase se dá no próprio CBI-S, que aparece na oração como um sujeito. O termo "cultural", além disso, foi acrescido ao enunciado traduzido e confere uma maior precisão aos procedimentos descritos no resumo da pesquisa.

Já no final desses resumos, a modificação ocorreu na supressão da negativa, presente no abstract ("The Portuguese CBI-S showed adequate reliability and validity but did not show cross-cultural validity"), e sua reformulação mediante o uso da palavra "ausência" que, a rigor, conservaria o mesmo sentido equivalente ("O CBI-S apresentou adequada confiabilidade e validade, entretanto, verificou-se ausência de estabilidade transcultural"). 0 que houve, no entanto, foi uma mitigação do impacto exercido pelo enunciado, o que não ocorre quando se usa termos negativos. Essa escolha, a princípio, pauta-se por um critério puramente estilístico.

Enfim, a partir das constatações obtidas pela leitura e análise do corpus, em consonância com as discussões teóricas até então empreendidas, pode-se endossar as considerações 
feitas logo no início deste exercício de aplicação, que denotam uma predominância de um caráter prescritivo do fazer tradutório, manifestado principalmente pela prevalência da tradução literal nos textos estudados, em que se deve perseguir uma obediência ao texto original como forma de preservar não somente o sentido do texto-fonte, mas o saber científico nele contido, seus conceitos, fórmulas e quaisquer outros dados denotativos. A linguagem científica, textualizada a partir da sobrevalorização dos elementos da semântica discursiva (em detrimento de outros níveis do percurso gerativo do sentido), privilegia os enunciados de natureza tanto temática (por conter descrições e formulações lógico-conceituais) quanto figurativa - ao mencionarem dados de existência concreta ou constatável - e são esses elementos que se articulam e configuram um efeito de verdade, que legitimariam seu caráter veridictório (parecer-ser verdadeiro), com finalidades igualmente cognitivas (voltadas ao fazer-saber do enunciatário) quanto persuasivas (um crer-ser verdadeiro por parte desse enunciatário).

Por sua vez, verifica-se que essa adesão à literalidade não se deu de forma estrita, mas entremeada por uma série de desvios cometidos pelo enunciador-tradutor, demonstrando que esse caráter prescritivo do fazer tradutório mostra-se flexível, em diferentes gradações, conforme as amostras escolhidas para análise. Ao se recorrer às transposições, esse caráter desviante mostrou-se mínimo, consoante à literalidade majoritária no fazer tradutório dos enunciadores em questão. Contudo, a intensidade desse grau se elevou mediante o recurso às modulações, em que os ajustes no enunciado mostraram-se mais significativos. A maior liberdade nas operações de tradução, nesse caso, teve como consequências a ênfase ou obscurecimento de determinados elementos, o esclarecimen- 
to ou "enxugamento" de aspectos presentes nos resumos e, não raro, ajustes textuais para tornar a tradução mais compreensível e agradável aos leitores de língua portuguesa. Uma tradução literal nesse caso, ao contrário, poderia transmitir uma impressão de artificialidade ao texto (consequência das traduções decalcadas), ou mesmo de dúvida acerca das habilidades e conhecimentos do tradutor.

Para encerrar esse tópico, convém retomarmos os conceitos de Bassnnett (2005) acerca das perdas e dos ganhos no processo tradutório, já que isso se configurou de fato nos textos selecionados. 0 tradutor, modalizado em seu fazer pela liberdade (querer-fazer) e pela possibilidade (poder-fazer), somado às suas competências linguísticas e cognitivas (saber-fazer), ajustou o enunciado traduzido para acrescentar informações tidas como importantes (salvo alguns equívocos detectados) e, da mesma forma, simplificar ou omitir outras consideradas redundantes ou inadequadas à situação enunciativa. 0 desvio à literalidade cometido desse modo não pode ser considerado como uma intervenção "abusiva”, ainda que tenha havido perda de alguma informação ou acréscimo de outras. Tal gesto pode ser compreendido como uma práxis enunciativa com orientação mais renovadora (ainda que sob limites estritos), que mobiliza gestos do enunciador-tradutor voltados ao ajustamento de seu enunciado ao público de destino, com o objetivo de torná-lo mais compreensível - e eficaz - na transmissão de um determinado saber científico.

\section{Considerações finais}

Os propósitos deste artigo voltaram-se especialmente a desbravar uma perspectiva de estudos ainda pouco explorada, especialmente no cenário brasileiro, que é conjugar os 
estudos da tradução com a semiótica francesa. É possível dizer que, dentro dos limites estabelecidos, pudemos oferecer algumas considerações gerais sobre aspectos do processo tradutório que podem ser analisados e interpretados com base no legado greimasiano.

A primeira delas, considerada crucial, foi colocar os estudos tradutórios sob uma perspectiva enunciativa, que permitiu compreendê-los como um processo envolto por uma série de variáveis, pertinentes ou não ao sistema linguístico, e que somente desse modo é possível entender o fazer tradutório não simplesmente como um procedimento puramente técnico, pautado na substituição de palavras e sintagmas de uma língua pelos de outra, mas que evidencia e fortalece o caráter dessa atividade como reconstrutora de sentidos, e alça o enunciador-tradutor como um protagonista desse processo - em vez de um simples executor de tarefas.

Esse último aspecto remete à segunda consideração importante deste trabalho: a relação do tradutor perante o texto. A partir do enquadre teórico-metodológico subsidiado pela semiótica greimasiana, foi possível estabelecer, ainda que em caráter sucinto e provisório, dois papéis principais que o enunciador-tradutor pode assumir em sua práxis. A primeira, mais conservadora, pauta-se pelo paralelismo com o idiomafonte e se vale de procedimentos tradutórios que visam a preservar a estrutura léxico-gramatical e semântica do original, como a tradução literal e a transposição. A segunda, mais liberal, confere maior poder de intervenção do enunciador em modificar estruturalmente o enunciado-fonte com vistas à manutenção e comunicação do sentido geral do texto, e pautase por procedimentos mais "invasivos" como a modulação e a adaptação. 0 grau de intervenção do tradutor pode assumir uma faceta mais intensa, quando se tratar de textos literários 
e poéticos, ou mais extensa, em caso de textos referenciais como os estudados neste artigo.

Fica evidente o caráter introdutório e, até certo ponto, desbravador deste trabalho em relação ao campo de estudos o qual se dispõe a abordar. Do mesmo modo, entende-se que muitas das considerações apresentadas necessitam ser corroboradas por estudos posteriores e se fazem necessárias pesquisas de maior fôlego para se debruçar sobre aspectos mais complexos, que foram abordados aqui muito brevemente entre tantos outros deixados de lado. Entretanto, acredita-se que esta iniciativa sirva como impulso para novos empreendimentos nesse entrecruzamento entre semiótica e tradução - cujo potencial é bastante rico, promissor e, por que não, fascinante.

\section{REFERÊNCIAS}

\section{AUBERT, F. H. Introdução à Metodologia da Pesquisa} Terminológica Bilíngue. 2. ed. São Paulo: Humanitas, 2001 (Cadernos de Terminologia, n. 2).

- Modalidades de tradução: teoria e resultados. TradTerm, São Paulo, v. 5, n. 1, p. 99-128, 1998.

. As (in)fidelidades da tradução: servidões e autonomia do tradutor. Campinas: Editora da Unicamp, 1993.

- Tradução literal: impossibilidade, inadequação ou meta? Ilha do Desterro, Florianópolis, n. 17, p. 185-192, 1987.

BARBOSA, H. G. Procedimentos técnicos de tradução: uma nova proposta. 3. ed. Campinas: Pontes, 2007. 
BASSNETT, S. Estudos de tradução. Porto Alegre: Editora da UFRGS, 2005.

BENVENISTE. E. Problemas de linguística geral I. 5. ed. Campinas: Pontes, 2005.

BERTRAND, D. Caminhos da semiótica literária. Bauru: Edusc, 2003.

CAMPOS, J. A. D. B.; CARLOTTO, M. S.; MAROCO, J. Copenhagen Burnout Inventory - student version: adaptation and transcultural validation for Portugal and Brazil. Psicol. Reflex. Crit., Porto Alegre, v. 26, n. 1, p. 87-97, 2013.

CATFORD, J. C. Uma teoria linguística da tradução. São Paulo: Cultrix, 1980.

ELHAMMOUMI, M. Marxist psychology: a research paradigm whose time has come. Estud. psicol. (Campinas), Campinas, v. 29, n. 1, p. 3-11, 2012.

FIORIN, J. L. Práxis enunciativa. In: PERNAMBUCO, J.; FIGUEIREDO, M. F.; SALVIATO-SILVA, A. C. (Orgs.). Nas trilhas do texto. Franca: Editora da Unifran, 2010. p. 53-74. (Coleção Mestrado em Linguística, v. 5).

As astúcias da enunciação: as categorias de pessoa, espaço e tempo. 2. ed. São Paulo: Ática, 2005.

FONTANILLE, J.; ZILBERBERG, C. Tensão e significação. Tradução de I. C. Lopes, L. Tatit e W. Beividas. São Paulo: Discurso/Humanitas, 2001.

GAUER, G. et al. Stressful events in autobiographical memory processing: Brazilian version of the centrality of event scale. Psicol. Reflex. Crit., Porto Alegre, v. 26, n. 1, p. 98-105, 2013. GREIMAS, A. J. Sobre o sentido: ensaios semióticos. Petrópolis: Vozes, 1975. 
Semântica estrutural. São Paulo: Cultrix/Edusp, 1973. GREIMAS, A. J.; COURTÉS, J. Dicionário de semiótica. São Paulo: Contexto: 2008.

HJELMSLEV, L. Prolegômenos a uma teoria da linguagem. Tradução de J. T. Coelho Netto. 2. ed. São Paulo: Perspectiva, 2009.

JAKOBSON, R. Linguística e comunicação. Tradução de I. Blikstein e J. P. Paes. 9. ed. São Paulo: Cultrix, 1977.

MITTMANN, S. Notas do tradutor e processo tradutório: análise e reflexão sob uma perspectiva discursiva. Porto Alegre: Editora da UFRGS, 2003.

MOREIRA, P. A. S. et al. Development and evaluation of psychometric properties of an inventory of teachers' perceptions on socio-emotional needs. Psicol. Reflex. Crit., Porto Alegre, v. 26, n. 1, p. 67-76, 2013.

MOUNIN, G. Os problemas teóricos da tradução. São Paulo: Cultrix, 1975.

NIDA, E. A.; TABER, C. R. The theory and practice of translation. Leiden: United Bible Societies, 1982.

POLCHLOPEK, S; AIO, M. A. Tradução técnica: armadilhas e desafios. Tradução \& Comunicação, São Paulo, n. 19, p. 101113, 2009.

PONDIAN, J. D. F. Linguística, semiótica, tradução: apontamentos: In: ENCONTRO DOS ALUNOS DE PÓSGRADUAÇÃO EM LINGUÍSTICA, 11, 2008, São Paulo. Anais... São Paulo: Paulistana, 2009. Disponível em: <http://www. fflch.usp.br/dl/xienapol/anais/PONDIAN_Juliana.pdf>. Acesso em: 02 abr. 2013. 
PROPP, V. I. Morfologia do conto maravilhoso. Rio de Janeiro: Forense Universitária, 1984.

SAUSSURE, F. Curso de linguística geral. Tradução de A. Chelini, J. P. Paes e I. Blikstein. 27. ed. São Paulo: Cultrix, 2006. SILVEIRA, B. A arte de traduzir. São Paulo: Melhoramentos/ Editora da UNESP, 2004.

TINAJERO, C.; PARAMO, M. F. The systems approach in developmental psychology: fundamental concepts and principles. Psic.: Teor. e Pesq., Brasília, v. 28, n. 4, p. 457-465, 2012.

Artigo recebido em janeiro de 2014 e aprovado em maio de 2014.

Disponível em: http://seer.fclar.unesp.br/casa 